\title{
Mavi Anadoluculuk ve Sabahattin Eyüboğlu'na Eleştirel Bakışlar
}

\author{
Emel KOŞAR*
}

\begin{abstract}
$\ddot{O} z$
1950’li yıllarda Mavi Anadolucular (Halikarnas Balıkçısı [Cevat Şakir Kabaağaçlı], Sabahattin Eyüboğlu, İsmet Zeki Eyüboğlu, Azra Erhat, Vedat Günyol, Faik Zeki İzer) “ana yurt” Anadolu’ya coğrafya temelli vatan anlayışı etrafinda baktılar. Batı medeniyetinin kaynağı olan Yunan medeniyetine (Antik Yunan efsaneleri, mitolojisi) değer verdiler. Bodrum'u merkez alarak Gökova Körfezi'ni denizden dolaşmaya dayanan "Mavi Yolculuk"lara çıktılar. Anadolu'yu tüm medeniyetlerin beșiği olarak gördüler. Kendilerini antik hümanist felsefenin mirasçıları olarak tanımladılar. Bir insanda bütün insanlığı gören hümanizma anlayışına yöneldiler. Antik Yunan'a ait değerleri benimseyerek Anadolu'yu kucakladılar. Halk oyunları, efsaneler, şiir, el işleri gibi kültürel ögelerin dış etkilerden çok yüzyıllarca Anadolu topraklarında kazandıklarımızla iç içe geçerek, birikerek meydana geldiğini savundular.

Gergedan'daki "Cumhuriyet için Hümanizma" adlı dosyada yazan yazarlar, (Murat Belge, Ekrem Işın, Ahmet Oktay, Enis Batur, Selim İleri) Mavi Anadolucular deyince ilk akıllarına gelen isimler, Sabahattin Eyüboğlu ve Halikarnas Balıkçısı olduğu için yazılarında onlar üzerinde dururlar. Murat Belge, Ekrem Işın, Ahmet Oktay ve Enis Batur'un ciddi üslûplarına karşın Ece Ayhan'ın üslûbu alaycı ve suçlayıcıdır. Selim İleri ise, deneme türündeki yazısında Mavi Anadolucular'ı ve kendisini samimi bir dille eleştirir.

Adı geçen dosyada Mavi Anadolucular Cumhuriyet aydını ve ideolojisi, Tercüme Bürosu ve Köy Enstitüleri, Osmanlı tarihine bakış ve modernleşme bağlamında ele alınmıştır.
\end{abstract}

Anahtar Kelimeler: Reşat Nuri, Yeşil Gece, yeni hayat, yeni öğretmen tipi, Cumhuriyet dönemi edebiyat1

\footnotetext{
* Dr. Öğr. Üyesi, Mimar Sinan Güzel Sanatlar Üniversitesi Fen Edebiyat Fakültesi Türk Dili ve Edebiyatı Bölümü.
} Elmek: emel.kosar@msgsu.edu.tr 


\title{
Critical Approaches to Mavi Anadoluculuk and Sabahattin Eyüboğlu
}

\begin{abstract}
In the 1950s, Mavi Anadolucular (Halikarnas Balıkçısı [Cevat Şakir Kabaağaçl1], Sabahattin Eyüboğlu, İsmet Zeki Eyüboğlu, Azra Erhat, Vedat Günyol, Faik Zeki İzer) approached to their motherland- Anatolia with a geography-based homeland mentality. They valued and appreciated the Greek Civilization (Ancient Greek legends, myths) as the origin of the Western Civilization. They sailed through Gökova Bay marking Bodrum as their center point, and they called the sejourneys "Mavi Yolculuklar" which means Blue Journeys. They regarded Anatolia as the melting pot of all the civilizations and themselves as the inheritors of the ancient humanist philosophy. They turned the irfaces to wards humanism which is the mentality of seeing the whole humanity in a single human being. They embraced Anatolia by embracing Ancient Greek values and customs in the first place. They argued that the cultural elements like the folklore, legends, poems, craftsmans hipetc. Came to being from the cumulative cultural experiences that were gained on the soil of Anatolia. Since when Mavi Anadoluculuk was mentioned, Sabahattin Eyüboğlu and Halikarnas Balıkçısı were among the first names that came to minds of the writers (Murat Belge, Ekrem Işın, Ahmet Oktay, Enis Batur, Selim İleri) of "Cumhuriyet için Hümanizma”, a document of the literature magazine Gergedan, the writers focused on the senames in their writings. In contrast to Murat Belge, Ekrem Işın, Ahmet Oktay and Enis Batur's serious wordings, Ece Ayhan has a rather mocking and accusing type of wording. On the other hand, Selim ileri criticises Mavi Anadoluculuk writers in his essays with a candidtone.

In the document mentioned Mavi Anadoluculuk writers, Republic an intellectuals and ideologies, Translation Bureausand Village Institutions were examined in the regard of modernis mand the Ottoman history..
\end{abstract}

Keywords: Mavi Anadoluculuk, Sabahattin Eyüboğlu, Anatolia, Ancient Greek 


\section{Giriş}

1940'lı ve 1950'li yıllarda "Mavi Anadolucular" (Halikarnas Balıkçısı, Sabahattin Eyüboğlu, Azra Erhat, İsmet Zeki Eyüboğlu...) Anadolu’ya coğrafî temelli vatan anlayışı etrafında bakarlar. Doğu'yla Batı'nın sarmaş dolaş olduğu medeniyetler beşiği Anadolu'nun tarihî değerlerini benimserler. Geçmişin yaşayan değer hâline gelmesi için bugünün süzgecinden geçmesi gerektiğine inanırlar.

Denemeleri, çevirileri, fotoğrafları ve belgesel filmleriyle Türkiye'nin dünüyle bugünü arasında köprü kuran Sabahattin Eyüboğlu; Yunus Emre'nin hoşgörüsüyle ve öğretmen edasıyla kaleme aldığı eserlerinde geçmişin değerlerine sahip çıkarak, eğitimin ve sanatın önemsenmesi gerektiğini vurgular.

Sabahattin Eyüboğlu yaşadığı toprakların geçmişinde bulduğu her değeri benimsemeyi ve eskiyi yeniden yaşatmayı amaçlar. Kültürde kopuşsuzluğu sağlamaya çalışır. Tabiattan ders alarak Anadolu'nun tarihini, coğrafyasını, kültürünü tanımaya, Anadolu insanını kucaklamaya çalışır ve imeceyi savunur.

\section{“Cumhuriyet için Hümanizma" Dosyası}

Gergedan'daki (Sayı: 7, Eylül 1987) "Cumhuriyet için Hümanizma" dosyasında ve daha sonra yayımlanan Ece Ayhan'ın yazısında (Sayı: 9, Kasım 1987) başta Sabahattin Eyüboğlu olmak üzere "Mavi Anadolucular" ve onların hümanizma anlayışları eleştirilerek kültürde sürekliliği sağlama çabaları göz ardı edilmiştir.

Murat Belge "Mavi Anadolu Hümanizmi"1 adlı yazısında, Cumhuriyet aydınının "kimlik" olarak "bütün tarihiyle Anadolulu olmak"1 önerdiğini ve bunun zamanla "Mavi Anadolucular" adıyla anıldığını söyler. Çıkış noktası Batı'nın hümanizmi olan bu anlayışın fikir babası Halikarnas Balıkçısı Cevat 1 Murat Belge, "Mavi Anadolu Hümanizmi”, Gergedan, Sayı: 7, Eylül 1987, s. 86-88. 
Şakir (“bir Anadolu şovenisti”), sözcüsü Sabahattin Eyüboğlu (Tarihte istediği “öz”ü bularak, hümanizmle Marksizm'i birleştirmeye çalışsa da ortak zemini ikisi bir yere kadar paylaşırlar.), akademik tarafı Azra Erhat'tır. Belge, yazısında bir akım hâline gelemeyen bu hareketin aydınlar arasında ancak bir yere kadar etkili olabildiğini ve kitle düzeyine hiç inmediğini belirtir.

Belge, Mavi Anadolucular'ın sürekliliği gündeme getirerek yararlı bir iş yaptıklarını söyler ve ekler: "Hititlerden başlayıp bu topraklara adım atan herkesi kızamık gibi yakalayan bir Anadolu kökenine indirgeyemeyiz.” (s. 88)

Belge, Mavi Anadolucular'ın "kültür köken” konusuna yaklaşımlarını Türkiye'nin kültürel tarihinde Türklük ve Müslümanlık dışında ögelerin de bulunduğunu vurgulamaları açısından yararlı bulsa da yöntemlerini nesnel ve bilimsel bulmaz.

Ekrem Işın "Cumhuriyet ve Hümanizm"2 adlı yazısında, Hümanist düşüncenin ilk defa tek parti iktidarında devletin resmî felsefesi olarak ortaya çıktığını ve Türk kültürü ile Avrupa kültürü arasında bir denge arayışını temsil ettiğini belirtir. Işın'a göre devletin lâik eğitim politikası, Köy Enstitüleri aracılığıyla pratikleştirilir. Hümanizm, Cumhuriyet döneminin modernleşme atılımı içinde, devletin resmî görüşünü sistematikleştirme ve Türk insanının zihin yapısını Batı ölçülerine uygun şekilde değiştirme çabasıdır. Sabahattin Eyüboğlu da 1940’’ı yıllarda filizlenen hümanist akımın en yetkin sözcülerinden biri ve Hititleri Türk sayma (Anadolu'yu bütün geçmişiyle benimseme) anlayışıııı temsilcisidir.

Selim İleri ise "Yetişme Yıllarım, Kafka'nın Böceği"3 adlı yazısında, gençlik döneminde (Kafka'nın Değişim'inin etkisi altında olduğu yıllarda [60'lı yılların sonu 70'li yılların başı]) kültür hayatımızda Anadolu'yu mavi bir yolculuk gibi eski altın uygarlıkların beşiği olarak görmek isteyen Sabahattin Eyüboğlu ile Osmanlı İmparatorluğu'nun özde ileri bir devlet yapısı üzerinde kurulduğunu ifade eden Kemal Tahir arasındaki çatışmadan söz eder.

İleri, Sabahattin Eyüboğlu'nun Mavi ve Kara'sında, Fatih'i Homeros'un 
destanına ulamak isteyen bakış açısını ve "Üç Turunçlar" masalıyla mitologya arasında kurduğu bağı şaşırtıcı, yersiz ve garip bulur. Ona göre, Mavi hümanizmanın asıl sözcüsü Halikarnas Balıkçısı'dır, çünkü o, bir tarih görüşünden çok coşkular ve duyarlıklar üzerinde durur.

Ahmet Oktay “Halikarnassos'dan Bodrum'a-Türkiye'de Hümanist Söylem'in Tarihçesi ve Ütopist Bir Aydın Hareketi Üzerine" adlı yazısında, kendini Türk hümanizmine ve Rönesansına adamış sanat adamı ve iyi bir çevirmen olarak gördüğü Sabahattin Eyüboğlu'nun tarih anlayışını açıladığı yazılarından hareket ederek "hoşgörü, halk ve emek" kavramlarını öne çıkarsa da onun savunduğu görüşlerin toplum tarafından benimsenmediğini söyler. Özellikle Yunus Emre'nin “emeğin sözcüsü” ve "pantheist”e dönüştürülmesi tehlikeli bulunmuştur. Mavi hümanizmadan "kuramsal bir yapı" değil, sadece güzel çeviriler ve telif ürünler kalmıştır.

Enis Batur da "Cumhuriyet Hümanisti için Profilden Vesikalık Fotoğraf"s adlı yazısında, misyoner olarak gördüğü hümanist aydınların (Cevat Şakir, Sabahattin Eyüboğlu, Azra Erhat, Orhan Burian, Vedat Günyol...) eğitimi ve çeviriyi önemsediklerini, dilde açıklığı ve yalınlığı, yöntemde imeceyi, üslûpta ise kalenderlik ve yaşama sevincini benimsediklerini söyler. Halkın aydınlatıcı kılavuzluğunu üstelenen hümanist aydınlar, Cumhuriyet'e karşı muhalif ve eleştirel bir tavır benimsemeyi akıllarından bile geçirmemişlerdir. Arkalarına aldıkları mirasın yumuşak özellikleriyle çelişen otoriter bir bakışla Osmanlı kültürünü reddetmişlerdir.

Hümanist aydınların çeviri metinlerinde ise, üslûp düzeyinde asıllarına ters düşen uygulamalar yer almıştır: "Montaigne sulandırıldı, Shakespeare ve Kafka yazmadıkları dillerden çevrildi, Hisar ve Cansever topa tutuldu.” (s. 102) Bütün bunlara rağmen Batur'a göre, Cumhuriyet hümanistlerinin programına yanlışları tekrarlamadan sık sık dönmek gerekir.

Ece Ayhan "'Prens Sabahattin' Eyüboğlu” adlı yazısında Gergedan'ın bir önceki sayısında (Sayı: 7, Eylül 1987, s. 86-102) yer alan "Cumhuriyet için

4 Gergedan, Sayı: 7, Eylül 1987, s. 97-100.

5 Gergedan, Say1: 7, Eylül 1987, s. 101-102.

6 Ece Ayhan, “'Prens Sabahattin' Eyüboğlu”, Gergedan, Sayı: 9, Kasım 1987, s. 50. 
Hümanizm" bölümündeki düşüncelere kendininkileri ekler. Ona göre, "Mavi Yolcular", "Türk çeviri hümanistleri” veya "Yeni Atatürkçüler”in içinde şair ve şiir yer almaz. "Mavi renkli bir Jön Türk olayı" ve "Cumhuriyet'in önemli bir çeviri olayı" diye nitelendirdiği kişiler, bir tarikatın üyesi gibidirler.

Ece Ayhan, Sabahattin Eyüboğlu'nu İsviçre'de sürgünde ölen ve Osmanlı hanedanından olan, liberal eğilimli 'adem-i merkeziyetçi' Prens Sabahattin'e benzetir. Tercüme Bürosu'na ve Köy Enstitüleri'ne katıldıklarını vurguladığ 1 "Mavi Yolcular"ın kırk yıldır Türkiye'de olup bitenlerden haberlerinin olmadığını (Çoğu 'zadegân'[meşhur ve asil aileden olan] ve varlıklıdır.) söyler. Onları, toplumdan ve edebiyattan kopuk olmakla suçlar.

"Cumhuriyet için Hümanizma" adlı dosyada yazarların Mavi Anadolucular deyince ilk akıllarına gelen isimler, Sabahattin Eyüboğlu ve Halikarnas Balıkçısı olduğu için yazılarında onlar üzerinde dururlar. Murat Belge, Ekrem Işı̂n, Ahmet Oktay ve Enis Batur'un ciddi üslûplarına karşın Ece Ayhan'ın üslûbu alaycı ve suçlayıcıdır. Selim İleri ise, deneme türündeki yazısında Mavi Anadolucular'ı ve kendisini samimi bir dille eleştirir.

Adı geçen yazarlar, okumalarının temeline sosyolojik bakışı yerleştirerek Mavi Anadolucular'1 Cumhuriyet rejiminin sözcüleri olarak görürler. Osmanlı kültürünü reddettikleri, Hititleri Türk saydıkları ve halktan kopuk oldukları için onların toplum tarafından benimsenmediklerini vurgularlar. Mavi Anadolucular'ın sözcüsü Sabahattin Eyüboğlu ise, çevirmenliğiyle ön plâna çıkar.

1950'li yıllarda yurdunu seven, ona sahip çıkan ve tanıtan kişilere "mavi" denilirdi. "Mavi Yolculuk"un temelinde de yurt sevgisi, insanların tarihlerini ve yaşadıkları coğrafyayı benimsemeleri vardır.

Mavi Anadolucular, Köy Enstitüleri aracılığıyla aydınla halk arasındaki uçurumu kapatmaya çalışırlar. Sadece Batı medeniyetini referans almazlar, eğitime ve sanata önem vererek Anadolu'nun tarihine ve kültürüne yönelirler. Aydınlanmanın sadece Batı medeniyetini örnek alarak değil, halk kültüründeki (türkü, halk hikâyesi, ninni, bilmece, kilim, nakış...) süreklilikle (özellikle resim ve müzikte) birlikte sağlanabileceğini savunurlar. Eski ve yeni arasındaki 
benzerliklere değinerek geçmişle gelecek arasında bağ kurarken bir insanda bütün insanlığ̀ görürler.

\section{Sonuç}

"Cumhuriyet aydını", "Mavi Anadolucu", "hümanist" diye tanımlanan, ismi Halikarnas Balıkçısı ve Azra Erhat'la birlikte anılan Sabahattin Eyüboğlu özellikle Köy Enstitüleri ve eğitim hakkındaki görüşleri sebebiyle devletin resmi görüşünü savunmakla ve halkla bütünleşememekle suçlanır. Deneme türünün en iyi örneklerini veren, kitapları, çevirileri ve filmleri hâlâ ilgi gören Eyüboğlu geçmişe farklı bir pencereden bakar. Eserleriyle halk kültürü geleneğini yeniden üretmeyi amaçlar.

Kültürde geçmişe doğru gittikçe uygarlıklar arasında benzerlikler ve ortak özellikler artar. Çok yönlü kültür adamı Sabahattin Eyüboğlu'nun Hititleri Türk sayıp saymaması değil, Anadolu'yu bütün geçmişiyle benimseme ve ona sahip çıkma anlayışı önemlidir. Eyüboğlu'nun meseleye toplum mühendisliği açısından baktığına dair görüşlerin yanına Hümanizm anlayışına adapte olabilmiş bir yerlilik anlayışıyla, tarihsellik meselesine coğrafya ve estetik temelli bir tercihle baktığı görüşü de eklenebilir. $\mathrm{O}$, tarihimizde halk kültürü geleneğini sürdürmeye çalışan ve Anadolu insanının sıcaklığını yansıtan farklı bir sestir. 


\section{Kaynakça}

“Cumhuriyet için Hümanizma”, Gergedan, Say1: 7, Eylül 1987, ss 85-102

Batur, Enis. “Cumhuriyet Hümanisti için Profilden Vesikalık Fotoğraf”, Gergedan, Sayı: 7, Eylül 1987, ss 101-102

Belge, Murat. “Mavi Anadolu Hümanizmi”, Gergedan, Sayı: 7, Eylül 1987, ss 86-88

Ece Ayhan. “'Prens Sabahattin’ Eyüboğlu”, Gergedan, Sayı: 9, Kasım 1987, ss 50

Işın, Ekrem.“Cumhuriyet ve Hümanizm”, Gergedan, Sayı: 7, Eylül 1987, ss 89-92

İleri, Selim.“Yetişme Yıllarım, Kafka’nın Böceği”, Gergedan, Sayı: 7, Eylül 1987, ss 93-96

Koşar, Emel. Sabahattin Eyüboğlu'nun Denemelerinde Sanata Bakıļ, E Yayınları, İstanbul, 2013

Oktay, Ahmet. 'Halikarnassos'dan Bodrum'a-Türkiye'de Hümanist Söylem'in Tarihçesi ve Ütopist Bir Aydın Hareketi Üzerine”, Gergedan, Say1: 7, Eylül 1987, ss 97-100

Uğurcan, Sema. "Sabahattin Eyüboğlu Üzerine Bir Portre Denemesi”, Sabahattin Eyüboğlu Kitabı, Haz: Emel Koşar, Mühür Yayınları, İstanbul, 2014, ss 11-19. 